\title{
POLICE OFFICERS' VULNERABILITY AS A CHALLENGE FOR CHEMICAL DISASTER MEDICAL SUPPORT
}

\author{
E. Valkanova*, R. Kostadinov, R, Etova, M. Georgieva \\ Department of Epidemiology and Disaster Medicine, Faculty of Public Health, \\ Medical University of Plovdiv, Bulgaria
}

\begin{abstract}
Processes of industrialization and globalization lead to increase of chemical incidents of various magnitude. Toxicity of the great majority of chemical elements and compounds applied in industrial processes, causes imminent threat to the affected population. Police officers are those responsible for safeguarding the area of chemical damage.

The aim of this study is to analyze police officers' vulnerability in case of chemical disasters that pose a specific challenge towards medical support.

By the means of descriptive method hazards to the police officers health are presented. Comparative and deductive analysis are performed in order to assess policemen vulnerability in case of chemical area of damage. Cluster analysis is applied for medical support challenges related to the measured vulnerability levels.

Based on analyses of the last years' chemical incidents the main risk factors leading to increase vulnerability are listed. The significance of personal protective equipment in case of chemical incidents is well known by the policemen that in most of the cases are the first entering in contact with the casualties. In most of the cases they have no background information. This requirement for extremely rapid and detailed incident assessment is the prerequisite to chemically affected policemen reduction. Unfortunately, few of the training programs include chemical threat assessment.

The review and analyses of chemical incidents where policemen became casualties highlights the requirement for broaden medical training for the police officers.
\end{abstract}

Key words: vulnerability, chemical incident, policemen, disaster medical support

\section{INTRODUCTION}

Industrialization and globalization have inevitable impact on population health and wellbeing. As undeniable as the benefits are, the risk and hazards should also be acknowledged. Many of the raw materials used in manufacture are harmful and have the potential for serious damage to life and health of the affected. The EU-28 level of production of chemicals hazardous to population in 2016 was 201 million tons. (1) Despite the efforts, the chemical industry is causing an abundance of accidents with release of toxic substances. They vary from domestic incidents, to road traffic accidents, terrorist attacks and industrial accidents. The impact on the population could be insignificant or devastating, like the disaster

\footnotetext{
* Correspondence to: Elena Vladimirova Valkanova, Department of Epidemiology and Disaster Medicine, Faculty of Public Health, Medical University of Plovdiv, Bulgaria, e-mail: e.v.valkanova@gmail.com
}

in Bhopal, India where 18000 died and over 100000 were affected. (2)

Bulgaria is a developing country and chemical industry has significant importance for the economy, contributing to higher productivity, gross domestic product and a better external trade for specific products like soda ash, mineral fertilizers, petrochemicals, cellulose and some others. The companies in the field are 643. Leading companies are Solvay Sodi, Lukoil-Neftochim, Agropolichim, Neochim, Svilosa and Orgachim. (3)

Reported accidents during the recent years involve broad spectrum of chemicals including sulphur dioxide, benzene, butane, LPG, propane, crude oil, cokes gas, hydrochloric acid, vegetable oil, hydrocarbons, ammonia, methane, barium chloride, cyanides, chlorine, vinylchloride. (4) 
In case of chemical accidents, the entire chain for assuring the population life, health and wellbeing is activated. Police officers are among the first responders answering the signal and arriving at the spot. Their professional duty is to safeguard the area of damage, to restrict the access and exit and to facilitate disaster relief activities of all rescue teams. Their role in the entire relief operation is of utmost importance. Throughout execution of the variety of duties police officers are exposed to the impact of the same damaging factors as the affected population is. This exposure increases the levels of risk they take in every chemical incident. Preparedness and skill to act in contaminated environment is the key to a safe execution of their tasks. In order to assure their operability a detailed analysis on police vulnerability and required preventive measures has to be performed.

\section{AIM}

The aim of this study is to analyze police officers' vulnerability in chemical accidents and the specific challenges it poses towards medical support of the population.

\section{MATERIALS AND METHODS}

By the means of descriptive method hazards to the police officers health are presented. Comparative and deductive analysis are performed in order to assess policemen vulnerability in case of chemical area of damage. Cluster analysis is applied for medical support challenges related to the measured vulnerability levels.

\section{RESULTS AND DISCUSSION}

The characteristics and circumstances of a community, system or asset that make it susceptible to the damaging effects of a hazard is defined as vulnerability. Decreasing vulnerability is one of the main opportunities for decreasing disaster risk. Approaches to vulnerability reduction include raising knowledge and awareness and also preparedness measures. $(5,6)$

The risk for the first responders, police officers included, arises from unfamiliar environment that in the majority of the cases is contaminated by unknown in the beginning toxic substance. Response activities sometimes start without any background information regarding the hazards. Moreover, in the great majority of the chemical incidents the background information available does not cover all hazards present in the area of damage. What is more, the unpredictable weather can rapidly change the direction of toxic spread and enlarge the area of damage.
VALKANOVA E., et al. Also, there is always a chance for secondary event that superposes additional damaging factors to the existing ones. (7)

A retrospective study of reports regarding 57 975 chemical accidents with 15000 injured and 354 dead was conducted. (8) From all of the affected, the majority were employees working at the affected sites or general public ( $80 \%$ or 12353 ). Responders to the incident $(1,398-9 \%)$ constitute limited amount of the injured. Fatalities occurred within $3 \%$ of the first responders. Another survey by studied exclusively chemical accidents where first responders were affected. (9) Police officers were the second most frequently injured group of first responders after the firefighters. The findings from the study depicts that Personal Protective Equipment (PPE) was used by firefighters frequently in comparison to the police officers, who did so rarely. One explanation given to the fact is related to the limited number of responders, who has received basic awareness-level hazardous material training.

From the performed analyzes, factors identified as manageable for increase of vulnerability are the lack of personal protective equipment and education and training for work in hazardous environment. (10) All hazards' PPE is compulsory for first responders, police officers included, arriving at the scene without any information regarding the hazards. As an example of the significance of these measures is the chemical accident in Pazardzhik involving propane-butane leakage that led to intoxication of at least 5 first responders. Despite the identified nature of the accident no one wore protective equipment, which caused hospital admission to 5 rescuers. (11)

The requirement for theoretical and practical training originates from the demand for substantial amount of skill and training needed to performing professional duties in full PPE. This is one possible explanation of the recorded reluctance to wear full equipment, unless it is necessary. Well known fact is that practice and training provide dexterity and confidence in the capabilities to perform duties.

Hazard identification and knowledge for appropriate behavior in dangerous environment is also paramount. One accident with chlorine leakage in Plovdiv affected several first responders and police officers were among the most severely injured. Despite the fact that chlorine has specific smell and could be easily identified, still there were casualties from 
exposure to it. (12) This highlights the usefulness of hazard identification courses as a part of assuring environmental pollution awareness for police officers. Actually, according to the official web site of the Ministry of Internal Affairs, the curriculum for police officers' education does not include a course on hazardous environment awareness and reaction. (13)

All aforementioned factors increase vulnerability and make police officers less effective in their task to safeguard the area of damage that have negative impact on the search and rescue activities, primary triage and organized evacuation. Provision of medical care close to the area is also affected - creates unsafe area for medical activities and increases the demand for emergency medical aid due to injured police officers. A delay in emergency restoration caused by disturbances in immediate recovery operations also affects medical support.

\section{CONCLUSIONS}

1. Lack of knowledge and skills for hazard identification, proper and safe behavior, adequate collective and personal protective equipment usage increase the chance of being affected by the damaging factor.

2. Increased risk level and insufficient training and capabilities make police officers more vulnerable to chemical accidents.

3. High vulnerability of police officers' decreases population resilience to disasters.

4. Inability to safeguard the area of damage (due to injuries sustained by police officers) obstructs medical support to the casualties.

5. Better theoretical and practical training is necessary for the police officers $9 n$ order to decrease their vulnerability in case of chemical incident.

\section{REFERENCES}

VALKANOVA E., et al.

1. http://ec.europa.eu/eurostat/statisticsexplained/index.php?title=Chemicals_prod uction_and_consumption_statistics

2. https://www.britannica.com/event/Bhopaldisaster

3. http://www.chemlandscape.cefic.org/wpcontent/uploads/pdfs/Bulgaria-57.pdf

4. http://www.factsonline.nl/

5. https://www.preventionweb.net/risk/vulnera bility

6. Beccari B. A Comparative Analysis of Disaster Risk, Vulnerability and Resilience Composite Indicators. Plos Currents [PLoS Curr], ISSN: 2157-3999; Vol. 8; 14 Mar 2016

7. Freitas R., Scene Safety and Situation Awareness in Disaster Response, Chiottone's Disaster Medicine, Second Edition, p. 255-262.

8. MA Duncan et al., Persons Injured During Acute Chemical Incidents-Hazardous Substances Emergency Events Surveillance, Nine States, 1999-2008, MMWR Suppl 64 (2), 18-24. 10 Apr 2015

9. Melnikova N, Wu J, Yang A, Orr M1. Acute Chemical Incidents with Injured First Responders, 2002-2012, Disaster Med Public Health Prep. (2):211-221. 12 Apr. 2018

10.http://www.who.int/hac/techguidance/ems/c hemical_insidents/en/

11.http://news.bnt.bg/bg/a/18-dushi-saobgazeni-ot-neizvesten-gaz-v-pazardzhik

12.https://www.24chasa.bg/Article/158901

13.http://mvr.bg/academy 